\title{
PEMBELAJARAN PEMROGRAMAN BERBASIS PROYEK UNTUK MENGEMBANGKAN KEMAMPUAN COMPUTATIONAL THINKING ANAK
}

\author{
Ade Nurhopipah $^{1 *}$, Indra Alan Nugroho ${ }^{2}$, Jali Suhaman ${ }^{3}$ \\ Program Studi Informatika, Fakultas Ilmu Komputer, Universitas Amikom Purwokerto, \\ Banyumas, Indonesia \\ * Penulis Korespodensi : ade nurhopipah@amikompurwokerto.ac.id
}

\begin{abstract}
Abstrak
Orientasi pembelajaran pemrograman pada anak tidak hanya bertujuan untuk menghasilkan produk teknologi, namun juga untuk membentuk computational thinking sejak dini. Kegiatan Pemrograman Pembelajaran Berbasis Proyek adalah metode pembelajaran melalui proyek untuk mengembangkan code literacy anak dengan memperkenalkan mereka pada dunia pemrograman dan aktivitasnya. Peserta kegiatan ini adalah siswa Sekolah Dasar di Purwokerto. Kegiatan dirancang sedemikian rupa agar menarik dan menyenangkan, sehingga siswa menganggap proses pembelajaran ini sebagai arena bermain. Bahasa pemrograman yang digunakan adalah Scratch dari MIT Media Lab. Setelah kegiatan ini, terdapat kemajuan peserta dalam aspek pengetahuan dan minat mereka dalam pemrograman. Peningkatan aspek pengetahuan peserta mencapai $22,83 \%$ dan peningkatan aspek minat peserta sebesar $8 \%$. Setelah mengikuti kegiatan ini, penguasaan Scratch peserta adalah 71\%. Dengan pencapaian tersebut, fasilitator menilai kegiatan ini cukup dapat mengenalkan penggunaan Scratch kepada peserta. Penilaian terhadap antusiasme peserta sebesar 88\% menandakan bahwa peserta menyukai dan menikmati proses pembelajaran serta menunjukkan bahwa kegiatan telah berjalan dengan baik dan memuaskan.
\end{abstract}

Kata kunci: Anak; Computational Thinking;Belajar Pemrograman Berbasis Proyek; Scratch.

\begin{abstract}
The orientation of learning programming for children does not only aim to produce technological products, but also to shape computational thinking at early ages. Programming Project-Based Learning is a projectbased method to develop children's code literacy by introducing them to the world of programming and its activities. The participants of this event were primary school students in Purwokerto. The activities were designed in such interesting and enjoyable ways that students consider this learning process a playground. The programming language used was Scratch from MIT Media Lab. After this event, participants make progress in aspects of knowledge and their interests in programming. The increasing of participants' knowledge aspect was $22.83 \%$ and the increasing of participants' interests aspect was $8 \%$. After taking part in this activity, participants' mastery of Scratch was $71 \%$. With this achievement, facilitators considered that this activity was adequate to introduce the use of Scratch to the participants. The evaluation on participants' enthusiasm was $88 \%$ which indicated that they liked and enjoyed the learning process and showed that the activity had run well and satisfyingly.
\end{abstract}

Keywords: Children; Computational Thinking; Programming Project-Based Learning; Scratch

\section{PENDAhuluan}

Penggunaan perangkat lunak di komputer, smartphone, tablet dan berbagai alat elektronik lain saat ini telah mendominasi kehidupan kita. Anak-anak semakin mudah terpapar oleh perangkat teknologi, bahkan mereka mulai menggunakannya sebelum belajar cara membaca dan menulis. Kondisi masyarakat yang berbasis perangkat lunak ini, membuat para pendidik merasa perlu membuat suatu program di mana anak-anak tidak hanya diarahkan agar melek dan bijak dalam menggunakan teknologi, namun juga dapat mendorong mereka mengerti bagaimana teknologi bekerja. 
Salah satu program yang dapat digunakan untuk memperkenalkan literasi digital adalah dengan belajar bagaimana membuat program dan menuliskan kode komputer yang dikenal dengan istilah code literacy. Orientasi belajar pemrograman untuk anak bukan hanya untuk menghasilkan produk teknologi, namun juga melatih computational thinking. Kemampuan ini dapat didefinisikan sebagai proses cara berpikir; abstraksi atau penggambaran masalah, dekomposisi atau penguraian masalah ke dalam bagian-bagian yang lebih kecil, menyusun algoritma penyelesaian masalah, evaluasi solusi, generalisasi pemecahan masalah lain dan otomasi dari solusi tersebut (Faber, dkk., 2017). Upaya peningkatan kualitas code literacy bukan hanya tentang bagaimana membekali anak untuk bekerja sebagai insinyur perangkat lunak, namun tentang upaya mempromosikan pentingnya computational thinking (F. García-Peñalvo, dkk., 2016).

Kemampuan computational thinking memungkinkan anak-anak untuk berlatih dalam hal logika berfikir dalam perumusan masalah, penyelesaian masalah, perancangan sistem, memahami konsep-konsep mendasar dalam ilmu komputer, dan melatih berfikir kreatif dan fleksibel (F. J. García-Peñalvo, dkk., 2018). Pendiri Apple, Steven Paul Jobs, bahkan mengatakan, "Everybody in this country should learn how to program a computer, because it teaches you how to think". Selain itu, pembelajaran coding dapat menumbuhkan sikap positif, melatih aktivitas metakognitif dan keterampilan sosial, serta menumbuhkan persepsi self-efficacy (kepercayaan diri) yang lebih baik (Özden \& Tezer, 2018).

Mengajarkan dasar komputasi dan pengkodean telah menjadi agenda pendidikan banyak negara di seluruh dunia. Pada tahun 2014, Inggris menjadi negara pertama di dunia yang menjadikan pemrograman komputer sebagai mata pelajaran wajib di semua tingkatan. Di Amerika Serikat, setiap negara bagian diberikan kebebasan sendiri dalam hal kebijakan mata pelajaran tersebut. Namun terdapat dukungan yang kuat dari pemerintah saat itu, misalnya adanya pernyataan Presiden Obama tentang pentingnya belajar cara membuat kode lebih dini. Sejak tahun 2016, siswa di Finlandia dari usia 7 tahun mulai mempelajari dasardasar pemrograman sebagai bagian dari kurikulum inti nasional (Tevfik Kaplancali \& Demirkol, 2017).

Dalam implementasi program pembelajaran ini, metode yang tepat harus dipertimbangkan agar kita tidak terjebak dengan metode pembelajaran konvensional. Kita harus menghindari metode yang hanya mentransfer pengetahuan tanpa menumbuhkan motivasi, mengembangkan skill dan potensi yang anak-anak miliki. Tantangan yang umum dihadapi dalam pembelajaran pemrograman meliputi keragaman tingkat kemampuan dan bakat anak, banyaknya pilihan software dan bahasa pemrograman, sifat pemrograman yang memakan waktu dan bagaimana menumbuhkan motivasi belajar anak. Oleh karena itu, perlu digunakan metode pembelajaran yang efektif dan sudah divalidasi secara eksperimental (Kalelioğlu \& Gülbahar, 2014).

Project-Based Learning (PBL) adalah sebuah inovasi pendekatan belajar berbasis siswa di mana guru beperan sebagai fasilitator. Siswa didorong melakukan pembelajaran sendiri dengan mengajukan pertanyaan yang sesuai keingintahuan dan minat mereka. Pendekatan PBL dapat digunakan dalam semua jenis mata pelajaran. Ismuwardani dkk., (2019) menerapkan metode PBL dalam melatih kreativitas dan kemandirian pada keterampilan menulis puisi. Hasil penelitian menunjukkan bahwa penerapan PBL dapat meningkatkan kreativitas dan kemandirian siswa secara signifikan. Memişoğlu (2011) meninjau PBL dalam meningkatkan keterampilan psikomotorik dan pemahaman konsep siswa dalam pembelajaran kimia. Penelitian ini menyimpulkan bahwa $85 \%$ siswa mencapai penguasaan pembelajaran pada aspek konsep dan aspek psikomotori.

Penelitian PBL yang diterapkan dalam kelas Ilmu Sosial menyatakan bahwa dengan metode ini, kelas menjadi lebih menyenangkan dan tidak monoton karena tidak berpusat pada guru. Pembelajaran dengan basis proyek memungkinkan anak-anak untuk lebih aktif selama pelajaran. Anak-anak juga menyatakan bahwa mereka lebih banyak dan mudah mengingat pelajaran karena mereka mencari tentang subjek itu sendiri, mengklasifikasikan informasi yang mereka temukan dan dapat menjelaskan tentang apa yang mereka ketahui kepada siswa lain (Sumarni, dkk., 2016). PBL juga dipakai sebagai metode yang disarankan digunakan dalam belajar pemrograman (Tevfik Kaplancali \& Demirkol, 2017). Metode berbasis proyek ini sangat tepat diimplementasikan dalam mengajar pemrograman karena dalam belajar pemrograman anak-anak belajar tanpa merasakan beban. Pembelajaran secara otomatis dilakukan dalam proses mereka menyelesaikan proyek secara mandiri dengan prinsip tanggung jawab, kreativitas dan kolaborasi.

Dalam pertemuan di Linz, Austria pada bulan Juni 2018 yang diselenggarakan oleh UNESCO, dilaporkan bahwa salah satu tantangan yang dihadapi dalam penyusunan kurikulum komputasi adalah, sulitnya bidang ini diterapkan di sekolah. Integrasi Ilmu Komputer dengan mata pelajaran lain dalam kurikulum sekolah juga dinilai tidak efektif. Saat ini, salah satu rekomendasi solusi yang diberikan pada pertemuan ini adalah memanfaatkan lebih banyak pembelajaran informal termasuk sumber daya dan kursus online (Storte \& Webb, 2019). Hal ini mengindikasikan bahwa sumber daya online sudah banyak tersedia dan dapat memenuhi kebutuhan belajar pemrograman. 
Namun, meskipun sumber daya informasi sudah begitu mudah diperoleh, dalam melaksanakan program ini terdapat beberapa kendala yang dihadapi. Masalah tersebut diantaranya adalah tentang pemilihan sumber informasi, konten materi pemrograman, bahasa dan lingkungan pemrograman serta metode apa yang digunakan agar tujuan pembelajaran dapat tercapai. Selain itu diperlukannya arahan dari seorang pengajar yang memiliki pengetahuan di bidang pendidikan dan pemrograman. Hal ini penting karena belajar pemrograman tidak sekedar hanya menulis code, namun juga diperlukan eksplorasi tentang hal baru dan juga perlunya siswa belajar dari kesalahan.

Purwokerto dikenal sebagai salah satu kota terpelajar karena memiliki banyak perguruan tinggi dan universitas. Namun begitu, kegiatan di bidang pemrograman khususnya untuk anak-anak masih belum populer. Dalam kegiatan Pengabdian kepada Masyarakat yaitu program Amikom Mitra Masyarakat (AMM), dosen dan mahasiswa Universitas Amikom Purwokerto melaksanakan kegiatan Pembelajaran Pemrograman Berbasis Proyek. Tujuan kegiatan ini adalah untuk melatih computational thinking anak dengan memperkenalkan dunia dan aktivitas pemrograman. Konsep kegiatan dibuat menyerupai taman bermain (playground) dan dirancang agar dapat menyentuh berbagai domain perkembangan anak baik pribadi, sosial moral, bahasa, kognitif, dan motorik (Bers, 2018). Selain itu, kegiatan ini, juga merupakan suatu upaya memperkenalkan pendekatan "Coding as Another Language" (CAL), yaitu prinsip bahwa belajar pemrogramman adalah belajar menggunakan bahasa baru untuk fungsi komunikasi dan ekspresi (Bers, 2019) .

\section{BAHAN DAN METODE}

Berdasarkan analisis situasi dan permasalahan yang telah diuraikan, maka kegiatan Pembelajaran Pemrograman Berbasis Proyek dirancang untuk menjadi solusi dari permasalahan tersebut. Desain kegiatan ini ditunjukan pada Gambar 1.

\section{Persiapan}

Sasaran peserta kegiatan ini adalah anak-anak usia sekolah pada level 4-5 di wilayah Purwokerto. Pembatasan usia dilakukan untuk membatasi kompleksitas materi, sehingga kegiatan lebih fokus dan mengarah pada tujuan yang diinginkan. Selain itu, pembatasan dilakukan untuk menjaring anak-anak yang memiliki minat khusus di bidang pemrograman.

Perkembangan teknologi saat ini membuat anakanak berpeluang untuk mendapatkan akses informasi yang lebih banyak. Teknologi mengubah cara anak-anak belajar, bermain dan berinteraksi (Ebrahimi, dkk., 2013). Dalam belajar pemrograman, terdapat berbagai pemrograman berbasis grafis yang memungkinkan anakanak membuat program dengan menyeret dan menjatuhkan perintah. Scratch adalah platform yang akan digunakan dalam aktivitas proyek pada kegiatan ini. Penggunaan Scratch untuk memperkenalkan pemrograman pada anak-anak telah dilakukan pada penelitian oleh Wilson, dkk., (2013), Boyer (2010) dan penelitian Wilson \& Moffat (2010). Dengan Scatch, anak-anak dapat menulis program dengan cepat dan menyenangkan tanpa adanya frustrasi dan kecemasan.

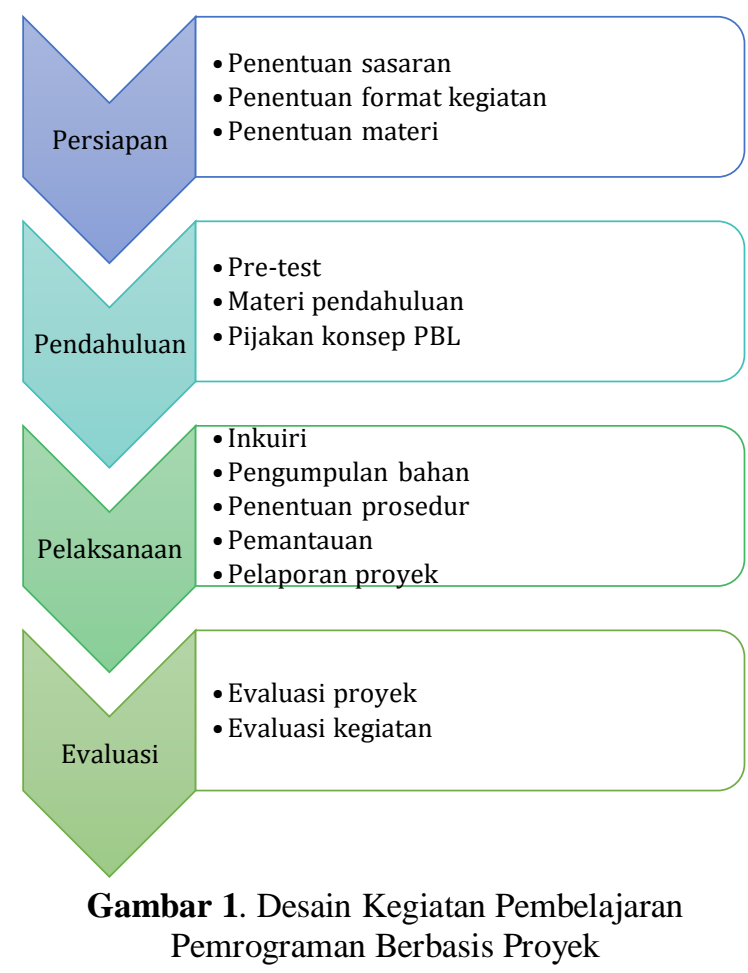

Kondisi pandemi Covid-19 yang belum berakhir, membuat kegiatan ini dilakukan dengan format daring dengan empat format yang dapat mengakomodir tujuan kegiatan sebagai berikut.

1) Pembelajaran kelas melalui Zoom. Kegiatan ini dilakukan untuk menyampaikan materi pembelajaran yang bersifat konseptual, menyampaikan arahan dan evaluasi proyek.

2) Pembelajaran dengan video tutorial melalui Youtube. Pemberian video tutorial untuk memberikan arahan teknis dan acuan pembuatan proyek mandiri.

3) Proyek mandiri melalui aplikasi Scratch. Pemberian tugas proyek mandiri diberikan dengan prinsip kebebasan ide, kreatifitas, eksplorasi, kolaborasi dan belajar dari kesalahan.

4) Pendampingan melalui Whatsapp group. Proyek mandiri memerlukan pendampingan intens dalam jangka waktu yang tidak singkat. Oleh karena itu disediakan forum diskusi yang dapat dimanfaatkan peserta sebagai sarana konsultasi. 
Tabel 1. Pembelajaran Pemrograman Berbasis Proyek dan Aspek Computational Thinking

\begin{tabular}{|c|c|c|c|}
\hline No & $\begin{array}{c}\text { Langkah Pembelajaran } \\
\text { Berbasis Proyek }\end{array}$ & $\begin{array}{c}\text { Aspek Computational } \\
\text { Thinking }\end{array}$ & Deskripsi \\
\hline 1 & $\begin{array}{l}\text { Penentuan target proyek } \\
\text { berbasis inkuiri. }\end{array}$ & Abstraksi masalah & $\begin{array}{l}\text { Peserta menentukan proyek dengan menggali } \\
\text { pertanyaan sesuai minat masing-masing. } \\
\text { Penentuan tujuan dilakukan dengan bimbingan } \\
\text { fasilitator berdasarkan pilihan proyek yang } \\
\text { diberikan. }\end{array}$ \\
\hline 2 & $\begin{array}{l}\text { Curah pendapat tentang } \\
\text { bahan-bahan yang } \\
\text { diperlukan. }\end{array}$ & Dekomposisi masalah & $\begin{array}{l}\text { Peserta dibantu fasilitator mengumpulkan materi } \\
\text { dan bahan yang dibutuhkan untuk membuat } \\
\text { proyek. }\end{array}$ \\
\hline 3 & $\begin{array}{l}\text { Menentukan prosedur } \\
\text { penyelesaian proyek. }\end{array}$ & $\begin{array}{l}\text { Penyusunan desain } \\
\text { algoritma }\end{array}$ & $\begin{array}{l}\text { Peserta mengidentifikasi langkah-langkah yang } \\
\text { harus diselesaikan tahap demi tahap. Peserta juga } \\
\text { dapat berdiskusi dengan patner untuk } \\
\text { berkolaborasi dan bertukar pikiran. }\end{array}$ \\
\hline 4 & $\begin{array}{l}\text { Melaksanakan dan } \\
\text { memantau sendiri } \\
\text { kemajuan proyek. }\end{array}$ & Penyelesaian masalah & $\begin{array}{l}\text { Peserta dan fasilitator membuat ceklis agenda } \\
\text { agar proyek yang dilakukan terlaksana dengan } \\
\text { baik. }\end{array}$ \\
\hline 5 & $\begin{array}{l}\text { Melaporkan dan } \\
\text { mengevaluasi target dan } \\
\text { tujuan. }\end{array}$ & $\begin{array}{l}\text { Evaluasi dan } \\
\text { Generalisasi }\end{array}$ & $\begin{array}{l}\text { Fasilitator mendampingi peserta untuk melakukan } \\
\text { evaluasi. Dalam fase ini juga dimungkinkan } \\
\text { adanya umpan balik baik dari peserta lain }\end{array}$ \\
\hline
\end{tabular}

Adapun materi yang disampaikan meliputi materi perkenalan terhadap profesi programmer dan materi pengenalan dasar pemrograman. Materi pengenalan dasar pemrograman meliputi konsep algoritma, perulangan (loop), dan pernyataan kondisional (if statement). Tiga konsep dasar ini diambil karena memainkan peranan penting dalam mengajar pemrograman (Tevfik Kaplancali \& Demirkol, 2017).

\section{Kegiatan pendahuluan}

Kegiatan dimulai dengan analisis kondisi peserta dalam aspek pengetahuan di bidang pemrograman, ketertarikan dalam dunia pemrograman dan penguasaan teknis terhadap software Scratch. Instumen pre test berupa kuisioner dengan skala Likert. Hasil kuisioner dievaluasi dengan menghitung indeks persentase dengan analisis interval. Selanjutnya kegiatan pendahuluan diberikan berupa penyampaian materi pengenalan dunia pemrograman. Pada kegiatan ini, peserta juga diberi informasi pijakan metode PBL agar pembelajaran dapat dilaksanakan dengan baik.

\section{Pelaksanaan Proyek Pemrograman}

Peserta dilatih dalam kemampuan computational thinking melalui penyelesaian sebuah proyek pemrograman dengan langkah-langkah seperti ditunjukan pada Tabel 1.

\section{Evaluasi}

Fasilitator berperan sebagai tempat berkonsultasi untuk memastikan peserta berada di jalur yang benar pada setiap fase. Fasilitator bertanggung jawab untuk memantau kegiatan siswa dengan merekam aktivitas siswa dalam menyelesaikan tugas proyek. Selanjutnya analisis peserta setelah kegiatan dilakukan dan dibandingkan dengan hasil analisis sebelum kegiatan. Selain itu dievaluasi tentang tingkat rasa senang peserta dalam proses pembelajaran dan juga tingkat kepuasan pendampingan dari fasilitator sebagai bahan evaluasi teknis pelaksanaan kegiatan.

\section{HASIL DAN PEMBAHASAN}

Kegiatan Pembelajaran Pemrograman Berbasis Proyek telah dilaksanakan pada tanggal 5-26 September 2020 dengan peserta dibatasi sebanyak 25 orang. Peserta berasal dari SDIT Harapan Bunda, SD Alam Baturraden, SD Qoryah Tayyibah, SD Al-Irsyad 01 Purwokerto, Kuttab Al-Fatih Sumampir, SDI Darul Falah, SD Puhua, SD UMP dan juga anak-anak pada komunitas Homeschooling.

\section{Kegiatan pendahuluan}

Kondisi peserta sebelum acara dianalisis berdasarakan hasil evaluasi kuisioner yang diberikan. Hasil evaluasi peserta sebelum kegiatan menunjukan bahwa indeks presentase rata-rata aspek pengetahuan peserta adalah $45 \%$. Meninjau masih rendahnya tingkat persentase pengetahuan peserta tentang dunia 
pemrograman, maka hal ini menjadi asumsi dasar untuk para fasilitator dalam memberikan materi yang sesuai dengan tingkat pemahaman peserta. Aspek ketertarikan peserta pada bidang pemrograman sudah cukup tinggi yaitu $76 \%$. Hal ini mungkin disebabkan karena program ini hanya diperuntukan bagi peserta yang memiliki ketertarikan di bidang pemrograman.

Namun demikian, setelah mengikuti acara ini, diharapkan aspek ketertarikan peserta dapat ditingkatkan. Demikian juga pada aspek pengalaman peserta menggunakan software Scratch masih tergolong rendah yaitu sebesar $41 \%$. Oleh karena itu, kegiatan ini akan memberikan pengalaman penggunaan Scratch kepada anak-anak sehingga keterampilan anak-anak dalam pengkodean menggunakan Scratch bisa meningkat.

Setelah analisis kondisi peserta sebelum kegiatan dilakukan, selanjutnya diberikan materi mengenai dunia pemrograman pada pertemuan 1 dan pertemuan 2 melalui aplikasi Zoom. Gambar 2 menunjukan proses penyampaian materi pada pertemuan 1 dan pertemuan 2 .

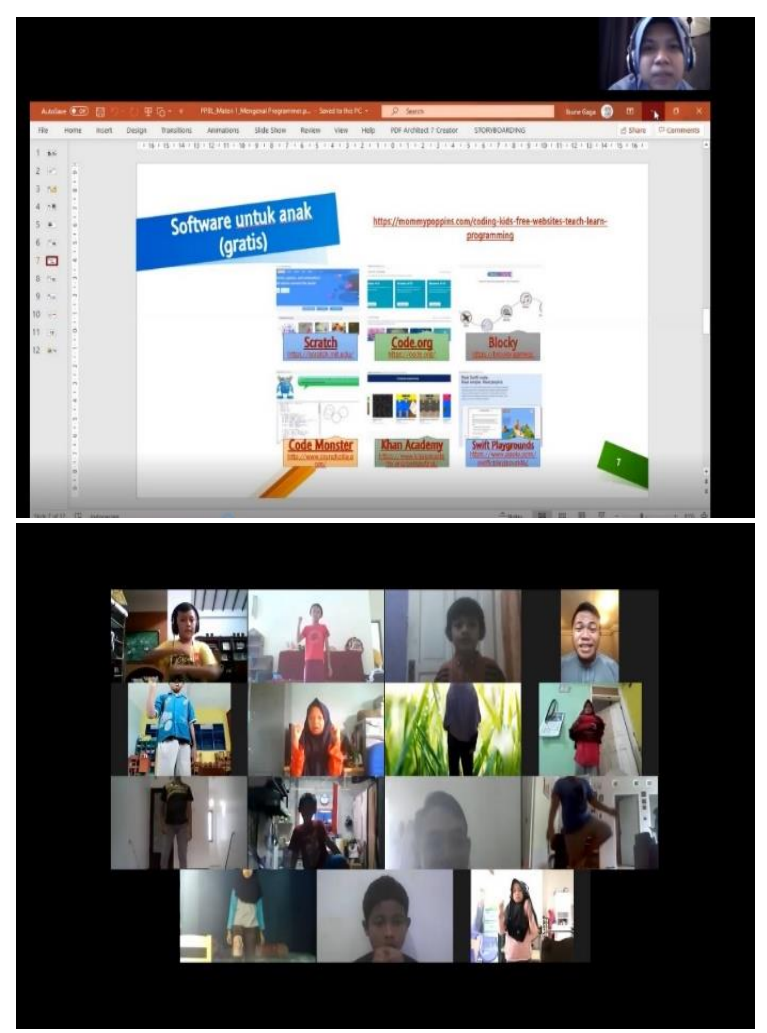

Gambar 2. Penyampaian Materi Melalui Aplikasi Zoom

\section{Pelaksanaan Pembelajaran Berbasis Proyek}

Pada pertemuan 1, peserta diberikan pijakan mengenai pembelajaran berbasis proyek yang terdiri dari proses pembelajaran melalui video tutorial, penugasan proyek mandiri untuk peserta dan pendampingan. Format video tutorial baik dijadikan sebagai acuan pembelajaran berbasis proyek, karena lebih fleksibel dapat dipelajari kapan dan dimana saja serta dapat dipelajari berulangulang. Oleh karena itu, peserta dapat membuat dan mengembangkan idenya lebih bebas berdasarkan pengetahuan yang diperoleh. Gambar 3 menunjukan cuplikan dari video tutorial yang diberikan kepada peserta. Adapun konten video tutorial diberikan adalah sebagai berikut.

1) Video Tutorial 1 : Mengenal Menu dan Membuat Akun Scratch.

Materi : Mengenal Scratch, mengenal menu-menu di website Scratch, membuat akun Scratch dan mengenal menu-menu pada Software Scratch.

2) Video Tutorial 2: Tutorial Animasi Huruf

Materi : Merubah warna sprite, memutar sprite, menambahkan suara, membuat sprite menari, merubah ukuran, kontrol keyboard, dan membuat sprite meluncur

3) Video Tutorial 3 : Tutorial Membuat Cerita dan Instalasi Scratch Desktop

Materi : Instalasi Scratch desktop dan membuat cerita meliputi membuat percakapan, membuat rekaman suara, memilih dan membuat animasi kostum, mengganti backdrop, membuat pesan / broadcast, menambah dan menggerakan objek pendukung.

4) Video Tutorial 4 : Tutorial membuat game roket di Scratch

Materi : Membuat objek terbang, membuat skor, membuat game berakhir (menang/kalah) dan mengatur tampilan.

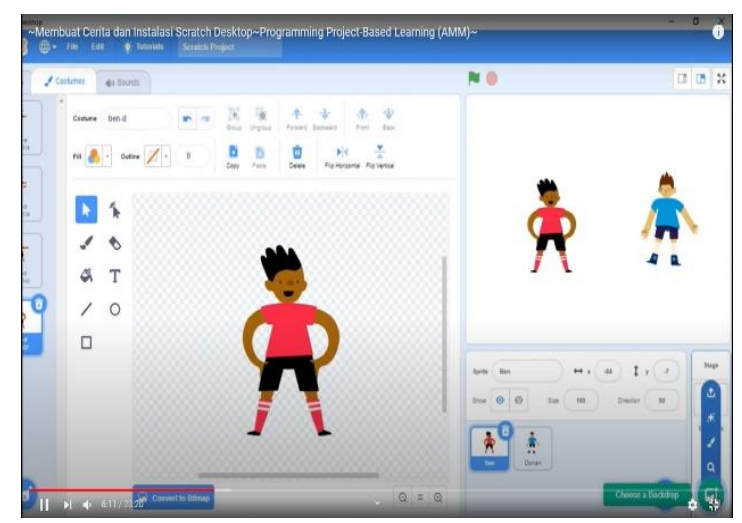




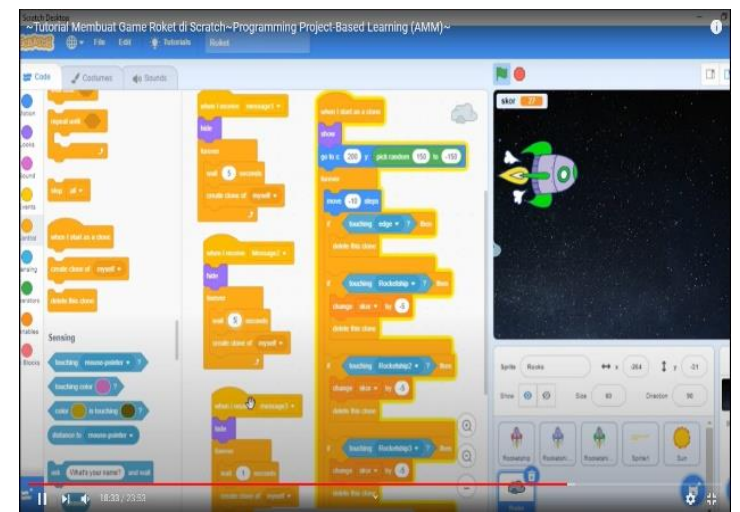

Gambar 3. Video Tutorial Belajar Pemrograman Berbasis Proyek

Setelah belajar melalui video tutorial, anak-anak diberikan penugasan mandiri sebagai berikut.

1) Proyek 1

a. Membuat akun di website Scratch

b. Membuat animasi sederhana menggunakan Scratch

c. Memilih dan mencoba tutorial yang menarik dari website Scratch

d. Unggah proyek enggunakan akun yang telah dibuat

e. Saling mengunjungi proyek teman yang sudah dibuat.

2) Proyek 2

a. Melakukan instalasi Scratch dan mencoba Scratch versi desktop

b. Membuat cerita dan/atau game sederhana menggunakan Scratch

c. Unggah proyek enggunakan akun yang telah dibuat

d. Saling mengunjungi proyek teman yang sudah dibuat.

Dalam mengerjakan proyek, peserta menentukan targetnya sendiri, dengan menggali pertanyaan sesuai minat masing-masing. Selanjutnya peserta mengidentifikasi bahan-bahan yang dibutuhkan untuk membuat proyek. Peserta kemudian menyelesaikan proyek dengan prosedur dan langkah-langkah sesuai arahan yang telah dipelajari dalam tutorial, melakukan ekplorasi sendiri atau berkonsultasi dengan fasilitator atas kesulitan yang dialami. Proses pendampingan adalah hal yang penting dilakukan untuk memastikan bahwa peserta memiliki sumber informasi yang dapat membantu mereka dalam menyelesaikan proyeknya. Setelah selesai membuat proyek, peserta melaporkan dan membagi proyek yang sudah dibuat di website Scratch yaitu https://scratch.mit.edu. Gambar 4 menunjukan kumpulan proyek yang telah diunggah peserta di website Scratch.

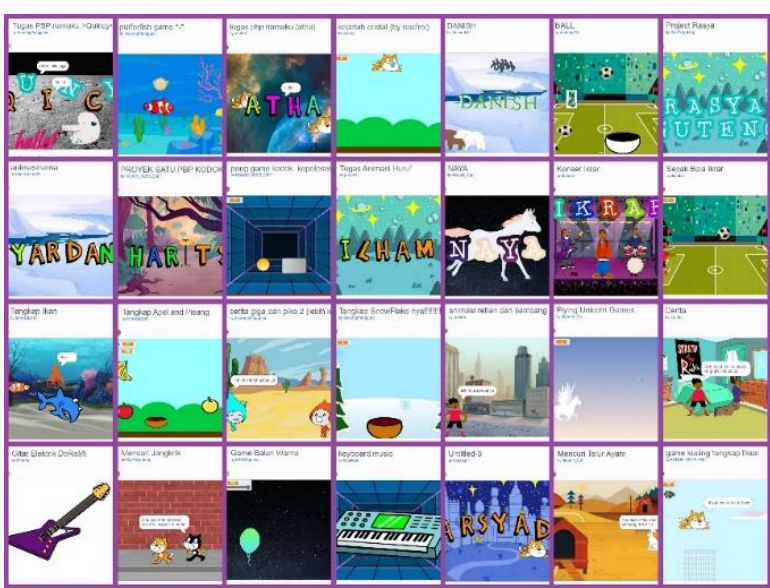

Gambar 4. Proyek Mandiri Peserta

Menggunakan Scratch

\section{Evaluasi}

Evaluasi proyek dilakukan melalui Zoom pada pertemuan ke-2 dan ke-3 yang ditunjukan pada cuplikan dalam Gambar 5. Dalam evaluasi ini, fasilitator meninjau hasil proyek mandiri peserta dalam aspek konsep misalnya ide, kreatifitas, alur proyek dan juga dalam aspek teknis yaitu kode dan penggunaan menu Scratch. Evaluasi ini diharapkan membuat peserta dapat memperbaiki proyeknya atau membuat proyek yang lebih baik dari proyek sebelumnya.
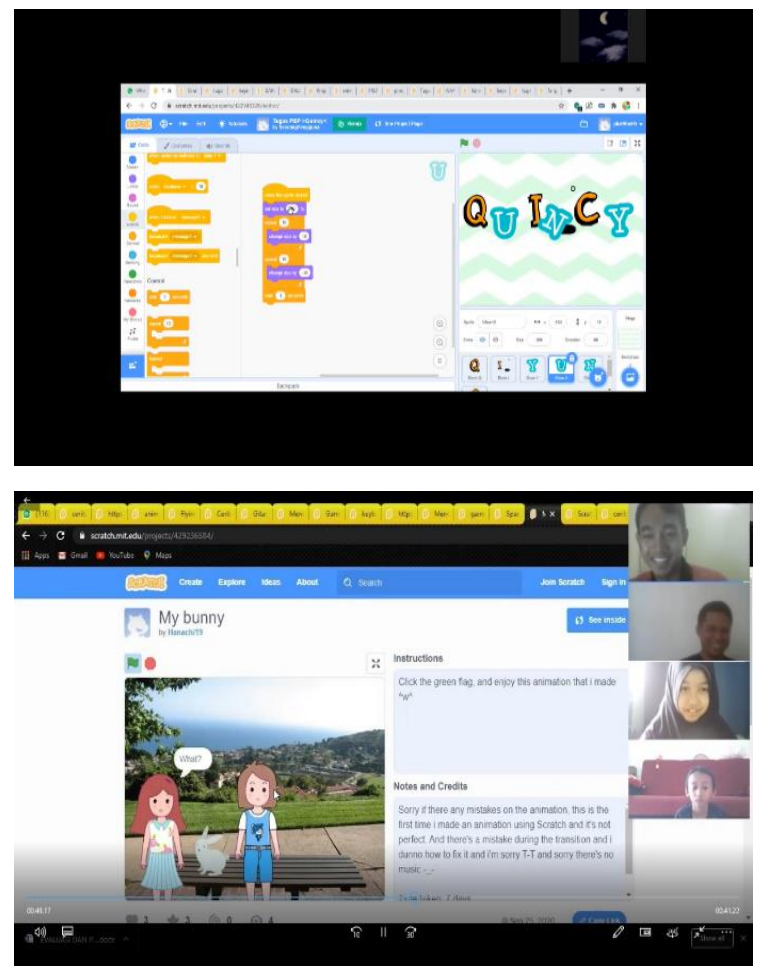

Gambar 5. Evaluasi Proyek Mandiri Oleh Fasilitator 
Setelah evalusi proyek dilakukan, selanjutnya dilakukan analisis kondisi peserta. Evaluasi ini berdasarakan hasil kuisioner yang diberikan pada peserta setelah rangkaian kegiatan. Perbandingan hasil evaluasi sebelum dan setelah kegiatan dari semua aspek yang telah ditentukan ditunjukan pada Tabel 2.

Tabel 2 menunjukan bahwa terdapat peningkatan yang cukup besar dalam aspek pengetahuan peserta sebelum dan sesudah kegiatan yaitu sebesar 22,83\%. Ketertarikan pada bidang pemrograman juga mangalami kenaikan walaupun tidak begitu signifikan yaitu sebesar $8 \%$. Setelah mengikuti kegiatan, penguasan peserta menggunakan Scratch menunjukan nilai sebesar $71 \%$. Dengan presentase sebesar ini, fasilitator menilai bahwa kegiatan ini cukup dapat memperkenalkan penggunaan Scratch terhadap para peserta. Evaluasi dalam aspek antusiasme peserta adalah sebesar $88,00 \%$ yang mengindikasikan bahwa peserta menyukai dan menikmati proses pembelajaran ini. Terakhir, aspek kepuasan terhadap fasilitator menunjukan nilai sebesar $87 \%$ yang menandakan pelaksanaan kegiatan telah yang berlangsung baik dan memuaskan.

Tabel 2. Indeks Persentase Aspek Penilaian Sebelum dan Setelah Kegiatan

\begin{tabular}{clccc}
\hline No & \multicolumn{1}{c}{ Aspek } & \multicolumn{3}{c}{ Persentase (\%) } \\
& & Sebelum & Sesudah & Selisih \\
\hline 1. & $\begin{array}{l}\text { Pengetahuan dunia } \\
\text { pemrograman }\end{array}$ & 45,00 & 67,83 & 22,83 \\
2. & $\begin{array}{l}\text { Ketertarikan pada dunia } \\
\text { pemrograman }\end{array}$ & 76,00 & 84,00 & 8,00 \\
3. & $\begin{array}{l}\text { Pengalaman } \\
\text { menggunakan Scratch }\end{array}$ & 41,00 & - & - \\
4. & Penguasaan Scratch & 71,00 & \\
5. & $\begin{array}{l}\text { Tingkat antusiasme } \\
\text { mengikuti acara }\end{array}$ & 88,00 & \\
6. & $\begin{array}{l}\text { Tingkat kepuasan } \\
\text { terhadap pendampingan }\end{array}$ & 87,00 & \\
\hline
\end{tabular}

Luaran yang diharapkan dari metode PBL selain diperolehnya wawasan baru adalah melatih keterampilan, komunikasi, tanggung jawab, kemandirian, disiplin, pemecahan masalah dan kepercayaan diri. Metode PBL juga dapat sangat berguna dalam melatih kolaborasi di mana siswa dan guru saling belajar satu sama lain (Maija \& Haatainen, 2019). Dalam pendekatan PBL, elemen kebebasan dalam memilih sangat penting untuk keberhasilan siswa. Diferensiasi ini memungkinkan siswa untuk mengembangkan sendiri minat mereka dan mendapatkan pembelajaran yang lebih dalam. Kebebasan ini memberikan motivasi bagi siswa sehingga mereka sering mencapai hasil yang lebih baik karena mereka mencoba membaca materi yang lebih menantang untuk mendapatkan informasi yang mereka cari (Bell, 2010).

Namun demikian, aspek kebebasan tampaknya tidak sepenuhnya berdampak baik terhadap seluruh peserta. Kebebasan bereksplorasi tanpa tekanan diharapkan membuat peserta lebih kreatif dan bertanggungjawab. Namun evaluasi dalam aspek penyelesaian proyek menunjukan bahwa hanya $60 \%$ peserta yang dapat menyelesaikan proyeknya sesuai standar yang diberikan. Sebagian peserta memang mampu menyelesaikan proyek mandirinya, bahkan melampaui ekspektasi fasilitator. Sebagian peserta lain membuat proyek namun tidak dibagikan atau diunggah di website Scratch. Sebagian peserta lain bahkan tidak selesai membuat proyek. Hal ini menunjukan bahwa aspek keragaman tingkat kemampuan dan bakat anak merupakan masalah yang belum dapat diselesaikan dalam metode pembelajaran PBL secara daring ini.

Evaluasi ini dapat menjadi gambaran bahwa dalam melatih computational thinking pada kegiatan ini masih terdapat beberapa hambatan. Dalam praktek pemrograman, peserta tidak dapat menyelesaikan proyek mandirinya namun juga tidak berani mengkomunikasikan kesulitannya kepada fasilitator. Motivasi peserta berkurang setelah menghadapi tantangan dan masalah yang dihadapi. Hal ini berkaitan dengan kurangnya kemampuan dalam belajar dari kesalahan. Peserta dinilai masih harus mendapatkan bimbingan intensif secara langsung. Faktor kendala tersebut mungkin dapat diatasi jika terdapat kerjasama yang baik antara fasilitator dan orang tua di rumah sebagai motivator dan fasilitator. Namun karena berbagai tantangan teknis pembelajaran di masa pandemi, tidak semua orang tua siap mendampingi anak-anak dalam kegiatan ini.

Tindak lanjut yang dilakukan oleh fasilitator adalah meneruskan fungsi pendampingan secara non formal sehingga diharapkan dapat tercipta sebuah forum konsultasi dan saling berbagi tentang referensi pemrograman. Kegiatan ini tentu saja hanyalah kegiatan stimulus untuk membantu anak-anak bereksplorasi, menemukan ketertarikannya, dan mengembangkan potensi softskill dan hardskill-nya. Diharapkan kegiatan terstruktur seperti ini dapat lebih rutin diselenggarakan oleh berbagai lembaga atau komunitas pendidikan lain agar manfaat yang diperoleh dapat lebih optimal.

\section{KESIMPULAN}

Kegiatan Belajar Pemrograman Berbasis Proyek (PPBL) dilakukan sebagai salah satu upaya melatih computational skill anak-anak. Pada kegiatan ini terdapat peningkatan aspek pengetahuan peserta, penguasaan menggunakan software Scratch serta ketertarikan peserta pada dunia pemrograman. Hal ini ditinjau dari evaluasi peserta sebelum dan setelah kegiatan. Kegiatan ini juga merupakan model pembelajaran yang disukai anak-anak yang ditunjukan dari evaluasi aspek kegembiraan yang dirasakan peserta sebesar $88 \%$.

Meskipun terdapat peningkatan yang cukup besar dalam aspek pengetahuan peserta sebelum dan sesudah kegiatan, namun rata-rata aspek pengetahuan sebesar $67,83 \%$ masih cukup rendah. Selain itu dalam 
penyelesaian proyek, baru $60 \%$ peserta yang dapat menyelesaikan proyeknya sesuai standar yang ditetapkan. Untuk mengatasi masalah tersebut, perlu dilaksanakan program terstuktur lanjutan. Selain itu kegiatan pembekalan dapat diberikan kepada para orang tua atau pendidik pada komunitas-komunitas pendidikan, untuk meningkatkan peran dan kapasitas mereka dalam mendukung pembelajaran pemrograman.

\section{UCAPAN TERIMA KASIH}

Penulis menyampaikan terimakasih kepada Lembaga Penelitian dan Pengabdian kepada Masyarakat (LPPM) Universitas Amikom Purwokerto yang telah memberikan dukungan untuk acara ini.

\section{DAFTAR PUSTAKA}

Bell, S. (2010). Project-Based Learning for the 21st Century: Skills for the Future. The Clearing House: A Journal of Educational Strategies, Issues and Ideas, 83(2), 39-43.

Bers, M. U. (2018). Coding, Playgrounds and Literacy in Early Childhood Education: The Development of KIBO Robotics and ScratchJr. 2018 IEEE Global Engineering Education Conference (EDUCON), April, 2094-2102.

Bers, M. U. (2019). Coding as Another Language: A Pedagogical Approach for Teaching Computer Science in Early Childhood. Journal of Computers in Education, 6(4), 499-528.

Boyer, J. T. (2010). Using Scratch For LearnerConstructed Multimedia: A Design-Based Research Inquiry of Constructionism in Practice. University of Florida.

Ebrahimi, A., Geranzeli, S., \& Shokouhi, T. (2013). Programming For Children; "Alice and Scratch Analysis." 3rd International Conference on Emerging Trends of Computer and Information Technology (ICETCIT 2013), (November 2013), 106-115.

Faber, H. H., Wierdsma, M. D. M., Doornbos, R. P., van der Ven, J. S., \& de Vette, K. (2017). Teaching Computational Thinking to Primary School Students via Unplugged Programming Lessons. Journal of the European Teacher Education Network, 12, 13-24.

García-Peñalvo, F. J., Reimann, D., \& Maday, C. (2018). Computational Thinking in the STEM Disciplines. In M. S. Khine (Ed.), Computational Thinking in the STEM Disciplines: Foundations and Research Highlights.

García-Peñalvo, F., Reimann, D., Tuul, M., Rees, A., \& Jormanainen, I. (2016). TACCLE 3, O5: An Overview of The Most Relevant Literature on
Coding and Computational Thinking with Emphasis on The Relevant Issues for Teachers.

Harlow, D. B., Dwyer, H., Hansen, A. K., Hill, C., Iveland, A., Leak, A. E., \& Franklin, D. M. (2015). Computer Programming in Elementary and Middle School. In Improving $K-12$ STEM Education Outcomes through Technological Integration (pp. 337-361).

Ismuwardani, Z., Nuryatin, A., \& Doyin, M. (2019). Implementation of Project Based Learning Model to Increased Creativity and Self-Reliance of Students on Poetry Writing Skills. Journal of Primary Education, 8(1), 51-58.

Kalelioğlu, F., \& Gülbahar, Y. (2014). Kalelioğlu, Filiz, and Yasemin Gülbahar. "The Effects of Teaching Programming via Scratch on Problem Solving Skills: A Discussion from Learners' Perspective.". Informatics in Education, 13(1), 33-50.

Maija, A., \& Haatainen, O. (2019). Project-Based Learning (PBL) in Practise Active Teachers' Views of Its' Advantages And Challenges. Integrated Education for the Real World, (June), 9-16.

Memişoğlu, H. (2011). The Effect of Project Based Learning Approach in Social Sciences Class on the Student Success and Memorability*. International Journal of Humanities and Social Science, 1(21), 295-307.

Özden, C., \& Tezer, M. (2018). The Effect of Coding Teaching on Students' Self-Efficacy Perceptions of Technology and Design Courses. Sustainability (Switzerland), 10, 1-29.

Storte, D., \& Webb, M. (2019). Coding , Programming and the Changing Curriculum for Computing in Schools.

Sumarni, W., Wardani, S., Sudarmin, S., \& Gupitasari, D. N. (2016). Project Based Learning (PBL) to Improve Psychomotoric Skills: A Classroom Action Research. Jurnal Pendidikan IPA Indonesia, 5(2), 157-163.

Tevfik Kaplancali, U., \& Demirkol, Z. (2017). Teaching Coding to Children: A Methodology for Kids 5+. International Journal of Elementary Education, 6(4), 32.

Wilson, A., Hainey, T., \& Connolly, T. M. (2013). Using Scratch with Primary School Children: An Evaluation of Games Constructed to Gauge Understanding of Programming Concepts. International Journal of Game-Based Learning, 3(1), 93-109.

Wilson, A., \& Moffat, D. C. (2010). Evaluating Scratch to Introduce Younger Schoolchildren to Programming. 22nd Annual Workshop of the Psychology of Programming Interest Group, (May 2012), 64-75. 